\title{
Modified Rain Attenuation Prediction Method Considering the Effect of Wind Direction
}

\author{
L. da Silva Mello, M. S. Pontes, I. Fagundes \\ Pontifical Catholic University of Rio de Janeiro, Rio de Janeiro, Brazil - smello@cetuc.puc-rio.br \\ M. P. C. Almeida \\ National Institute of Metrology, Quality and Technology, Rio de Janeiro, Brazil \\ F. J. A. Andrade \\ Federal University of Juiz de Fora, Juiz de Fora, Brazil
}

\begin{abstract}
The method currently recommended by the ITU-R for the prediction of rain attenuation in terrestrial line-of sight links considers an equivalent path length over which the rain intensity is assumed to be constant. In other methods, the spatial and temporal variations of the rainfall rate along the path are characterized by an effective rainfall rate that is dependent on the actual path length. Based on experimental measurements, this paper presents a modified effective rainfall rate method that includes the prevailing wind direction during rainy conditions as an additional parameter for the prediction of rain attenuation. The wind direction, which can be obtained from meteorological databases with global coverage, is shown to significantly improve prediction accuracy.
\end{abstract}

Index Terms - Rain attenuation, radio propagation, propagation measurements.

\section{INTRODUCTION}

Rain attenuation in terrestrial and earth-space links is due to scattering and absorption of the radio waves by the falling raindrops in the propagation path. Uniform rain can be characterized by a specific attenuation factor $\gamma_{R}$ that can be calculated from knowledge of the complex index of the refraction of water, the terminal velocity and the size distribution of the raindrops [1], [2]. For practical applications, an approximate power-law expression relating $\gamma_{R}(\mathrm{~dB} / \mathrm{km})$ and the rainfall rate $\mathrm{R}(\mathrm{mm} / \mathrm{h})$, first proposed by Drufuca [3], is given by

$$
R=k R
$$

Later, Olsen et al [4] provided tables of $k$ and $\alpha$ values for different frequencies and polarizations. Horizontally polarized waves are subjected to more attenuation than vertically polarized waves, as falling raindrops are deformed assuming the shape of oblate spheroids [5], [6]. For practical use, Recommendation ITU-R P.838-3 [7] gives expressions for the calculation of $k$ and $\alpha$ as functions of frequency, in the range of 1 to $1000 \mathrm{GHz}$, for vertically and horizontally polarized waves. These functions were developed as curve-fittings to power-law coefficients derived from scattering calculations carried out by Gibbins and Walden [8]. 
The attenuation due to rain in a fixed link can be obtained by integrating the specific attenuation along the propagation path. The rainfall rate field shows random space and time variations [9]. Time series of rainfall rate measured at a point usually show short periods of high rain rate embedded in longer periods of lighter rain. Rainfall is usually classified as lighter stratiform rain and consisting of smaller drops, or as convective rain, heavier and more localized. Spatial weather radar maps of reflectivity, which is a measure of rainfall intensity, show small areas of higher rain rate imbedded in larger regions of lighter rain and can be used to separate areas of convective and stratiform precipitation [10], [11]. Tropical rainfall is usually considered convective in nature, but almost all convection occurs in association with stratiform rain [12].

Methods developed to predict statistics of rain attenuation essentially differ in the models used to describe the space-time structure of rainfall rate. Synthetic storm methods convert time series of rainfall rate measured at a point into rainfall rate profiles along the path, using the translation velocity of the rain cells estimated as the wind speed, to derive attenuation statistics [3], [13], [14]. In recent years, extensive work has been conducted towards the development of synthesizers, based on the Maseng-Baken [15] stochastic model, that directly provide rain attenuation time series without relying on rainfall rate time series. Extensions of the original Maseng-Baken model have been developed for both earth-space [16] and terrestrial links [17].

Methods oriented to link design normally use the complementary cumulative probability distribution of point rainfall rate as the input to predict the corresponding attenuation distribution. The statistical profile of rain along the path is derived assuming a single cell of a particular shape [18] or multiple cells with a statistical distribution of sizes [19], [20]. Simpler methods for practical applications apply a reduction or adjustment coefficient to the actual path length to obtain an effective path length over which the rain intensity is assumed to be constant [21], [22], [23]. This concept is presently used in the rain attenuation prediction method recommended by the ITU-R [24].

An alternative approach is to characterize the statistical rain profile by an effective rainfall rate, which may be derived from the spatial correlation function of rainfall, derived from measurements using rapid response rain gauges spaced along a path [25] or from semi-empirical laws [26], [27].

This paper investigates a modified method for the prediction of rain attenuation in terrestrial lineof-sight links that includes the prevailing wind direction during rainy conditions as an additional parameter in the calculation of the effective rainfall rate, significantly improving prediction accuracy. The wind direction during rainy conditions was obtained from meteorological databases at locations for links for which rain attenuation and rainfall rate statistics are available in the ITU-R databanks [28]. 


\section{THE ITU-R PREDICTION METHOD}

The rain attenuation method recommended by the ITU-R [24] has the point rainfall rate exceeded for $0.01 \%$ of the time $\left(R_{0.01} \mathrm{~mm} / \mathrm{h}\right)$ as input to estimate the corresponding value of attenuation using the concept of an effective path length, $d_{e f f}$. According to the method, the attenuation exceeded for $0.01 \%$ of the time $\left(A_{0.01} \mathrm{~dB}\right)$ in a fixed terrestrial link is given by

$$
A_{0.01}={ }_{R} d_{e f f}=k R_{0.01} d r
$$

where $\gamma_{R}(\mathrm{~dB} / \mathrm{km})$ is the specific attenuation, $d(\mathrm{~km})$ is the path length and $r$ is a distance factor that depends on the frequency, on the path length and on $\alpha$, the exponent in the specific attenuation power law. The frequency and polarization dependent parameters, $k$ and $\alpha$, are given in Recommendation ITU-R P. 838-3 [6]. The point rainfall rate, $R_{0.01}(\mathrm{~mm} / \mathrm{h})$, for the link site is preferably obtained from long-term local measurements. If these are unavailable, which is often the case, it can be estimated from global maps provided by the ITU-R [29].

To obtain the attenuation, $A_{p}$, exceeded for a percentage of time $\mathrm{p}$ between $0.001 \%$ and $0.1 \%$, an extrapolation function is used:

$$
\frac{A_{p}}{A_{0.01}}=C_{1} p^{\left(C_{2}+C_{3} \log _{10} p\right)}
$$

where $C_{1}, C_{2}$ and $C_{3}$ are frequency dependent coefficients.

The use of only one value of rainfall rate cumulative probability distribution as representative of the rain regime in the region where the link is located represents a shortcoming of the method. For two regions with different distributions of point rainfall rate but similar values of $R_{0.01}$, the same statistical distribution for the attenuation will be predicted. Additionally, there is no reason why the distance factor should be dependent on frequency and on the $\alpha$ parameter. Although the regression using these variables provides a better fit to experimental data, the method is lacking in physical basis.

\section{EFFECTIVE RAINFALL RATE METHODS}

A method using the full rainfall rate distribution and the concept of an effective rainfall rate was developed as an alternative to the ITU-R method. Although effective path length methods are essentially equivalent of effective rainfall rate methods, the latter approach seemed preferable as the objective of this work is to investigate possible effects of the wind direction that govern the raincells movement. The general expression for predicting attenuation from an effective rainfall rate that represents the variations of rain along the path is given by: 


$$
A_{p}=k \cdot\left[R_{\text {eff }}\left(R_{p}\right)\right] \cdot d
$$

where $R_{p}$ is the rainfall rate exceeded during $\mathrm{p} \%$ of the time. For application in tropical climates, empirical expressions for the effective rainfall rate were obtained using a data set obtained from concurrent measurements of point rainfall rate and rain attenuation at 3 sets of converging links at different sites in Brazil, comprising a total of 17 links. The effective rainfall rate was first obtained as a function of the measured rainfall rate and the path length.

Having sets of converging links with different orientations and subjected to the same rain regimes at each of the three sites allowed us to investigate the effect of the wind direction on the attenuation. The influence of the wind on the cumulative distribution of rain attenuation in a point-to-point links is considered in synthetic storm methods and the can be explained considering the rain cells movement along the path. Depending on the relative angle between the path azimuth and the prevailing wind direction during rainy conditions, the portion of the propagation path the will be affected by the rain cells will change. It was found that the inclusion of this parameter in the modeling of the effective rainfall rate significantly improved the attenuation prediction accuracy.

Based on the good results obtained for the tropical sites, a second version of the method was developed considering data from other regions of the world available in the ITU-R databanks. The extended method also shows improved prediction accuracy in comparative tests with the ITU-R prediction method.

\section{A. Effective rainfall rate method for tropical regions}

The experimental data were obtained from tipping bucket rain gauge measurements of point rainfall rate and concurrently measured excess attenuation due to rain in 6 links in São Paulo, 4 links in Rio de Janeiro and 7 links in Brasília. Figure 1 shows the geometry of the converging links at the measurements sites.

Table I shows the location, duration of measurements, operation frequencies and path lengths for each link. Time resolution of the attenuation measurements was $10 \mathrm{~s}$ for São Paulo and $1 \mathrm{~s}$ for Rio de Janeiro and Brasília. The time series were analyzed to provide complementary cumulative distributions of rain attenuation. Information obtained from the rain gauge data includes the date and time of each bucket tip. Knowledge of the bucket rain accumulation and interval between tips allows for the creation of a time series of quasi-instantaneous rainfall rate, which was then analyzed to provide the complementary cumulative distributions of rainfall rate for each site. More detailed information about the measurement setup is given in [30]. 


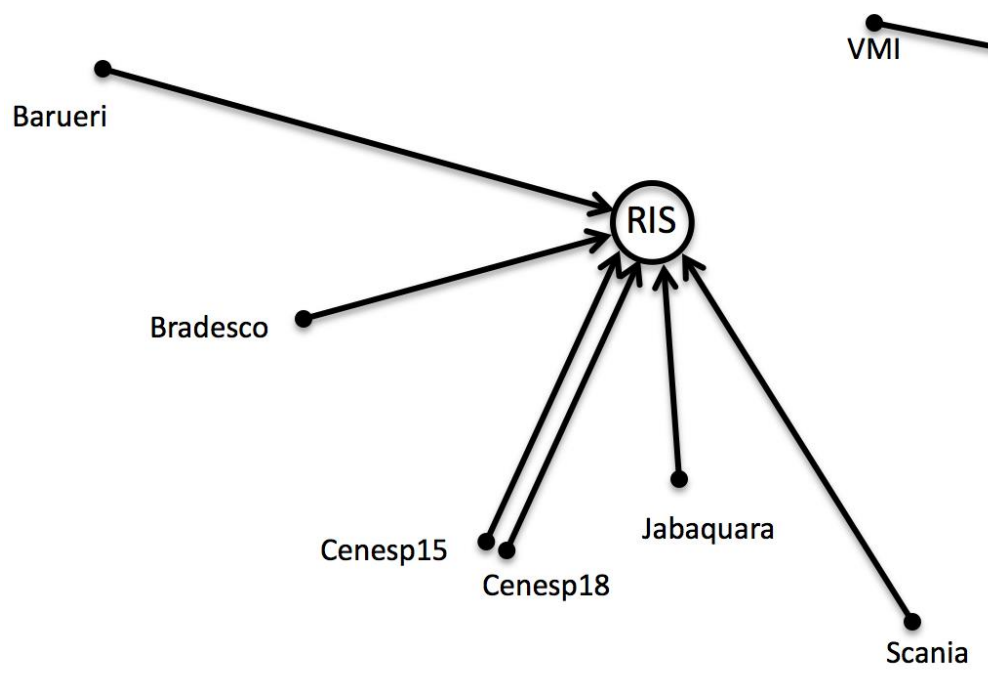

(a)

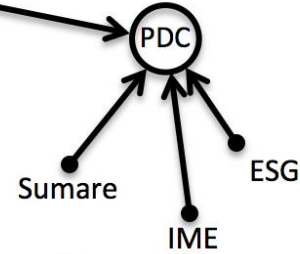

(b)

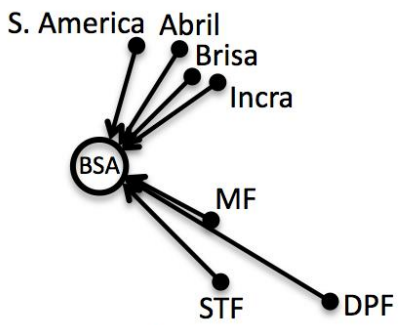

(c)

Fig. 1. Geometry of the converging links at (a) São Paulo, (b) Rio de Janeiro and (c) Brasília.

TABLE I - $\quad$ CHARACTERISTICS OF THE LINKS IN BRAZIL

\begin{tabular}{ccccc}
\hline Link & Site & $\begin{array}{c}\text { Path length } \\
(\mathbf{k m})\end{array}$ & $\begin{array}{c}\text { Frequency } \\
(\mathbf{G H z})\end{array}$ & $\begin{array}{c}\text { Measurement } \\
\text { period (years) }\end{array}$ \\
\hline Bradesco-RIS & São Paulo & 12.8 & 15 & 2 \\
Cenesp15-RIS & São Paulo & 12.8 & 15 & 2 \\
Cenesp18-RIS & São Paulo & 12.8 & 18 & 1 \\
Scania-RIS & São Paulo & 18.4 & 15 & 2 \\
Barueri-RIS & São Paulo & 21.7 & 15 & 1 \\
Jabaquara-RIS & São Paulo & 7.5 & 18 & 1 \\
Abril-BSA & Brasília & 1.1 & 38 & 1.5 \\
MF-BSA & Brasília & 1.0 & 38 & 1.5 \\
DPF-BSA & Brasília & 6.7 & 23 & 1.5 \\
Incra-BSA & Brasília & 1.2 & 23 & 1.5 \\
América-BSA & Brasília & 0.9 & 38 & 1.5 \\
STF-BSA & Brasília & 4.5 & 23 & 1.5 \\
Brisa-BSA & Brasília & 1.1 & 38 & 1.5 \\
IME-PDC & Rio de Janeiro & 5.6 & 15 & 2 \\
ESG-PDC & Rio de Janeiro & 5.2 & 18 & 2 \\
Sumaré-PDC & Rio de Janeiro & 5.1 & 23 & 2 \\
VMI-PDC & Rio de Janeiro & 22.0 & 15 & 2 \\
\hline
\end{tabular}

The effective rainfall rate values were estimated from the measured distributions of rainfall rate and attenuation using the following expression, derived from eq. (4):

$$
R_{e f f}\left(R_{p}\right)=\left(\frac{A_{p}}{k d}\right)^{1 /}
$$


Fig. 2 shows the calculated values of $R_{\text {eff }}$ against the measured values of $\mathrm{R}$ at the same time percentages for the $15 \mathrm{GHz}$ links in the São Paulo region, as an example. It can be observed that, for high values of $\mathrm{R}$, the effective rainfall rate tends to saturate at a value that decreases with the path length.

This can be explained considering that high rainfall rates are usually associated with smaller raincells, particularly true for tropical regions, were convective rain is common. As raincell size decreases, only part of the propagation path will be subjected to rain attenuation and the effective rainfall rate becomes increasingly smaller than the measured point rainfall rate.

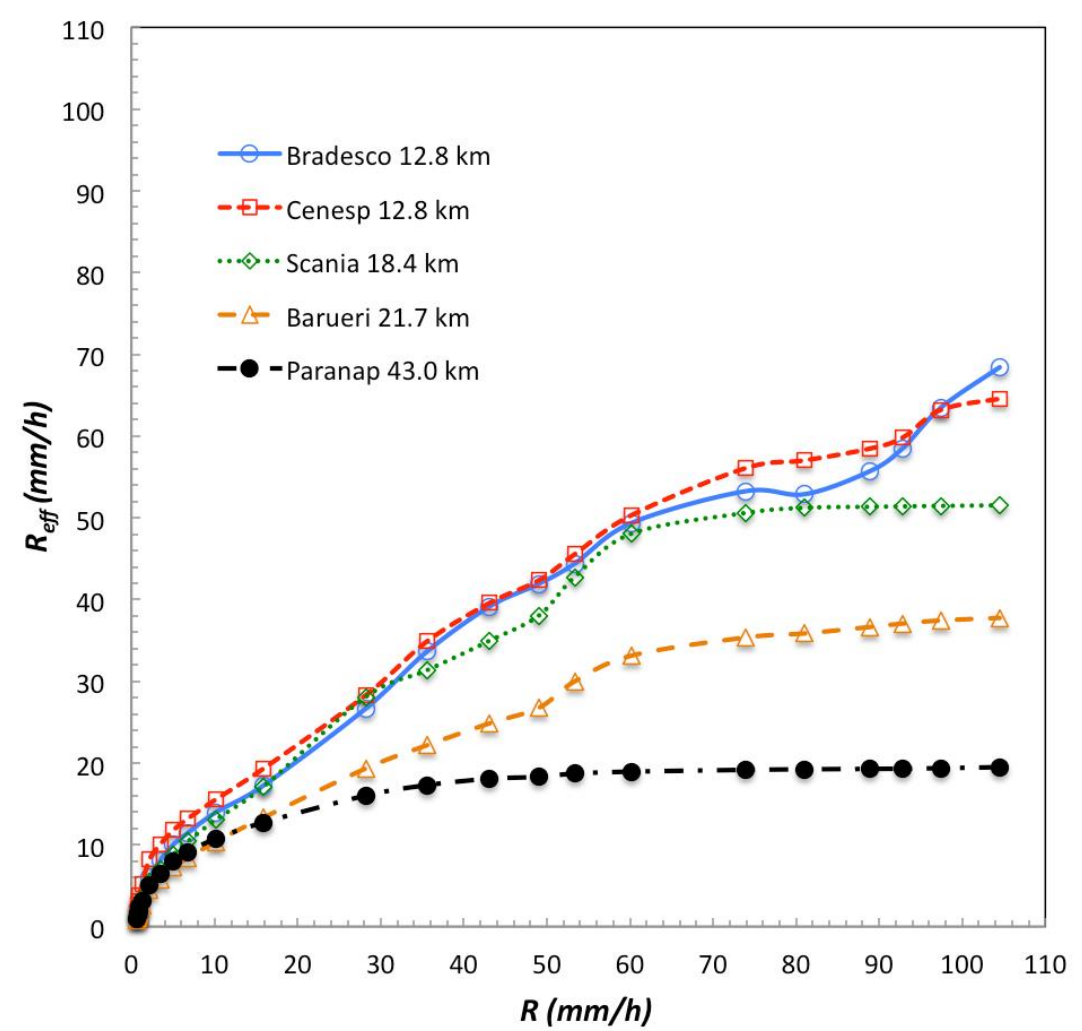

Fig. 2. Effective rainfall rate vs. measured rainfall rate $-15 \mathrm{GHz}$ links in Brazil

The behavior is well modeled by the following function:

$$
\begin{aligned}
& R_{\mathrm{eff}}\left(R_{p}, d\right)=\frac{R_{p} \times R_{0}(d)}{R_{p}+R_{0}(d)} \\
& R_{f}(d)=272 \exp (0.069 d)
\end{aligned}
$$

Eq. (7) was obtained by non-linear regression using data from the three measurement sites. The coefficient of determination [31] for the fitting is R-square $=0.93$. Figure 3 shows a scatterplot of the measured values of $R_{\text {eff }}$ and the values estimated using eqs. (6) and (7). 


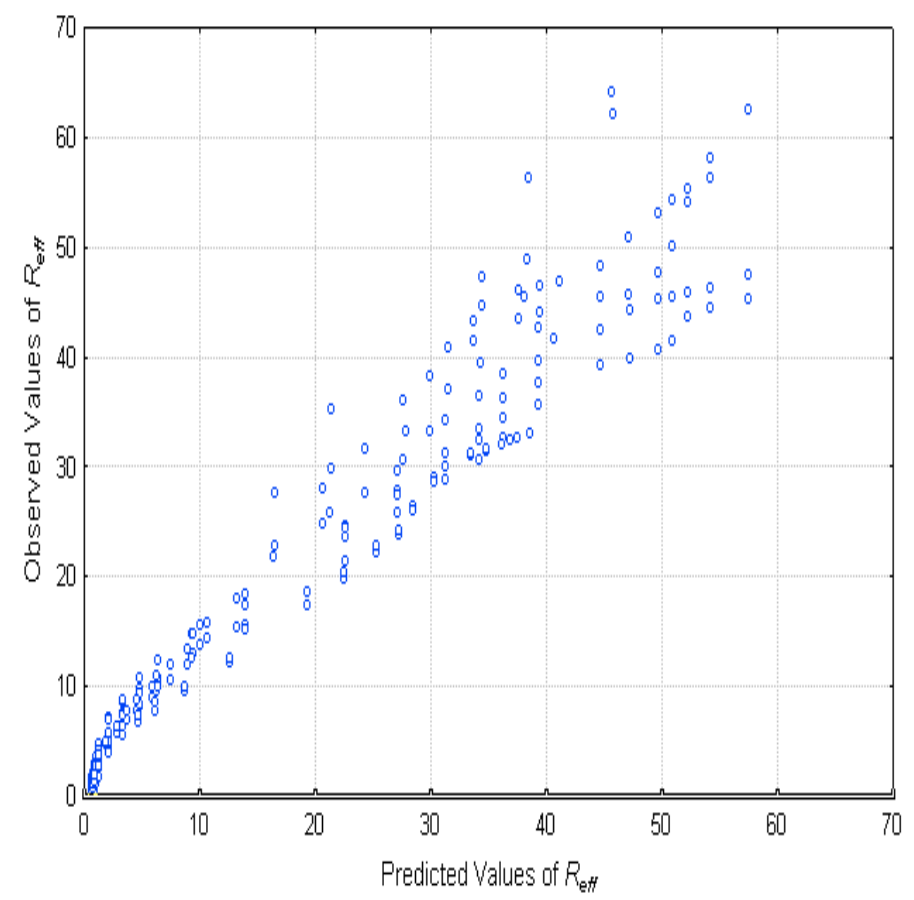

Fig. 3. Predicted versus observed values of $R_{\text {eff }}\left(R_{p}, d\right)$ for the links in Brazil

Although the result can be considered good, it is improved if the angle between the link azimuth and the prevailing wind direction at each site are included in the regression. The wind direction during rainy conditions was obtained from the ERA-40 database [32], which provides 40 years of global meteorological data, including both the average wind direction and the rain accumulation with 6-hour time resolution in a grid of 1.1250 per 1.1250 degrees. Data from this database were retrieved and analyzed to provide average values of wind direction for intervals with rain accumulation for the periods of measurement in each site. The values for each site were calculated by bi-linear interpolation using the values corresponding to the four nearest points in the grid. Fig. 4 shows one year of 6-hour resolution rain accumulation for the São Paulo (RIS) site and the distribution of wind direction during rainy conditions for the same period.

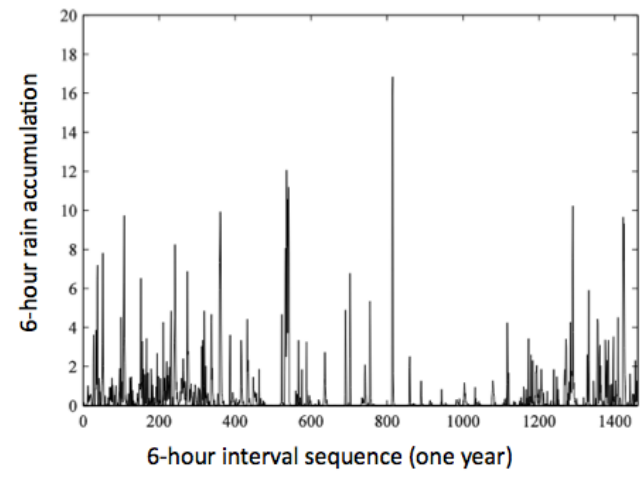

(a)

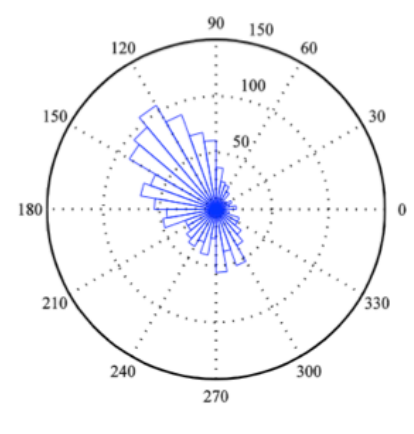

Wind direction

(b)

Fig. 4. Meteorological data for the São Paulo (RIS) site: (a) one-year rain accumulation with 6-hour resolution; (b) wind direction distribution for rainy periods. 
A new regression was obtained by including in the model the angle, $\theta$ (degrees), between the link direction and the prevailing wind direction. The best fit $(\mathrm{R}$-square $=0.96)$ is given by the following expressions:

$$
\begin{gathered}
R_{\text {eff }}\left(R_{p}, d\right)=\frac{R_{p} \times R_{0}(d)}{R_{p}+R_{0}(d)}(1+0.10) \text { for } 0 \quad 90 \\
R_{0}(d)=210 \exp (0.08 d)
\end{gathered}
$$

The corresponding scatterplot of measured and estimated values of $R_{\text {eff }}$ is shown in Figure 5. Figure 6 shows a comparison between the measured complementary cumulative distributions of rain attenuation for 4 links in São Paulo and the distributions predicted with the ITU-R method and the method proposed in this paper. The use of an effective rainfall rate depending on path length and wind direction improves the fitting, particularly for high values of rainfall rate.

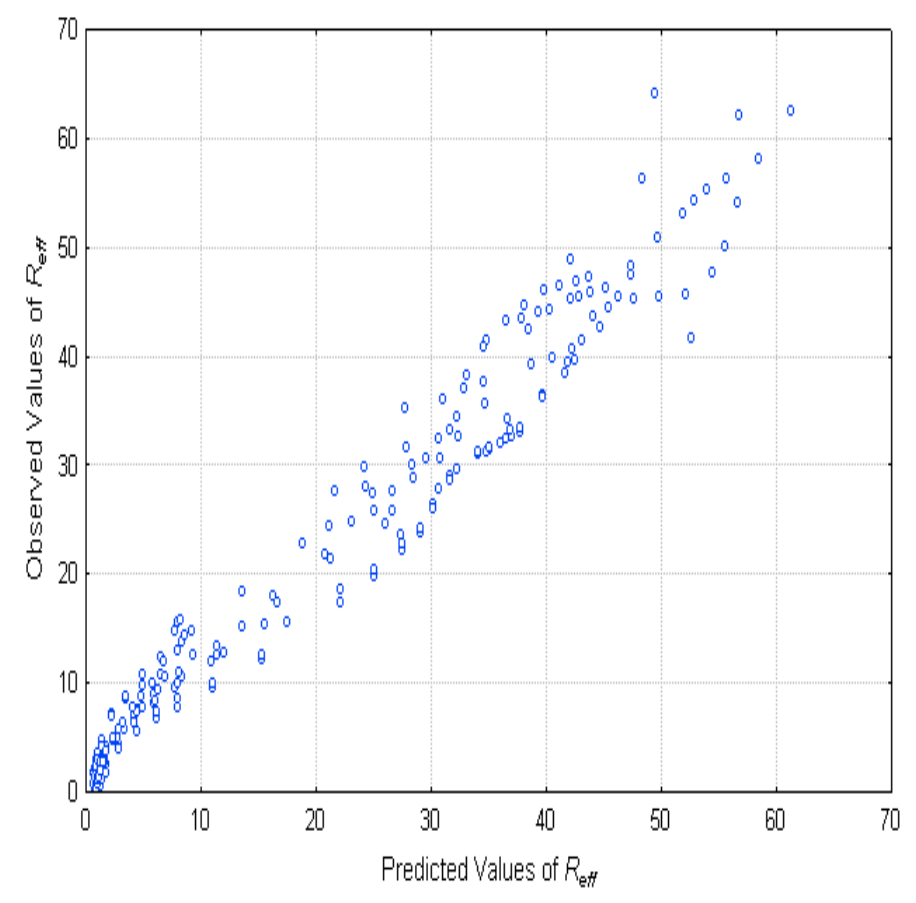

Fig. 5. Predicted versus observed values of $R_{e f f}\left(R_{p}, d, \theta\right)$ for the links in Brazil 


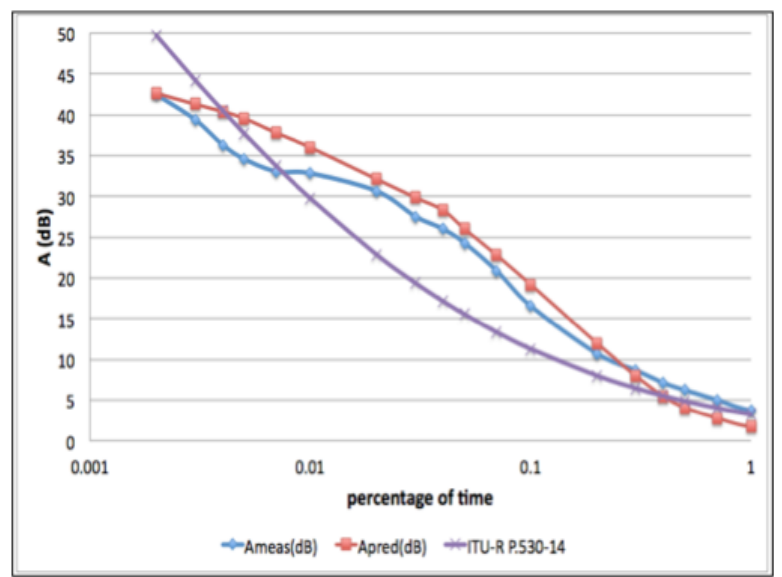

(a)

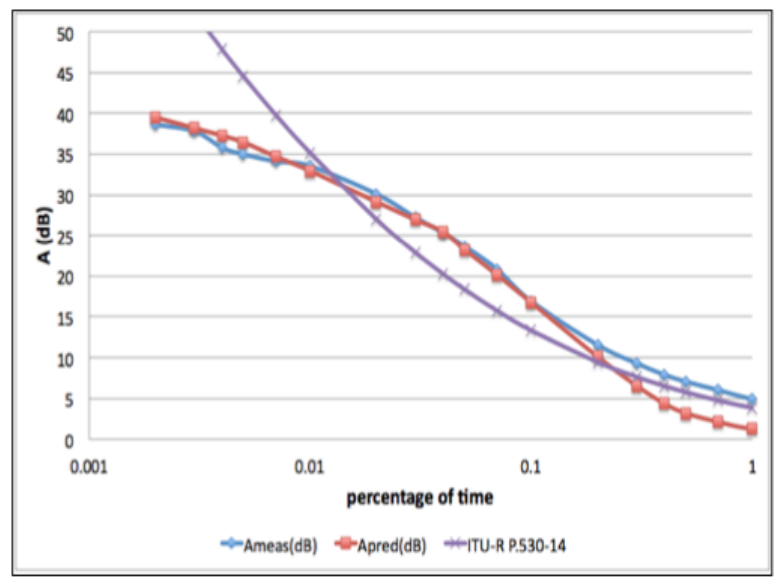

(c)

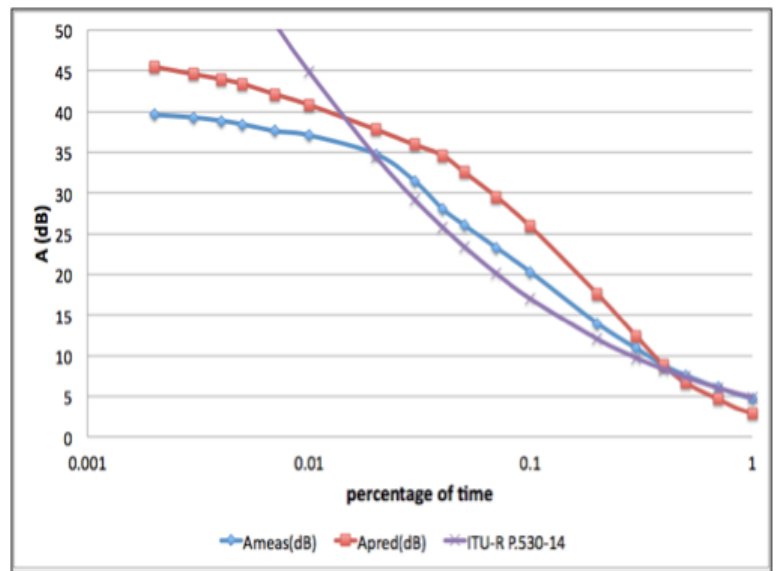

(b)

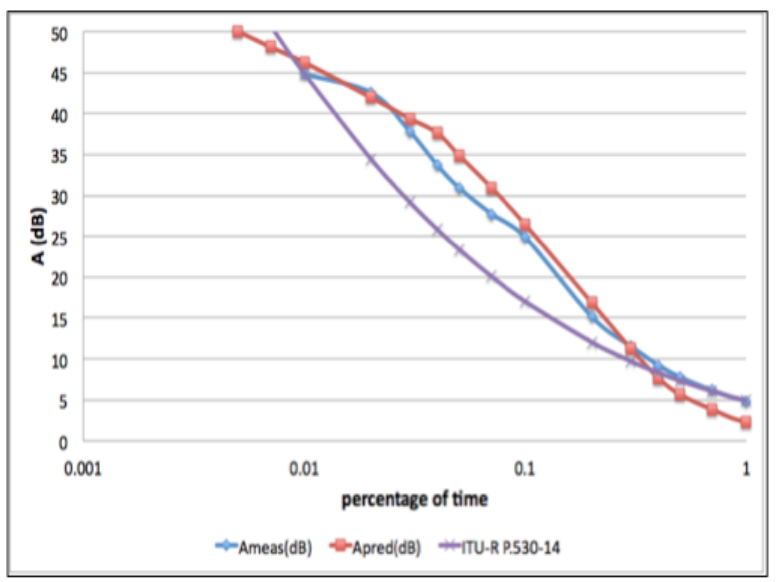

(d)

Fig. 6. Predicted and measured distributions of attenuation: (a) Bradesco-RIS; (b) Barueri-RIS; (c) Cenesp15RIS; (d) Scania-RIS.

\section{B. Extended effective rainfall rate method}

The method for tropical regions described in the previous section was generalized using 76 years of measured data of point rainfall rate and rain attenuation from 25 links in 7 countries, available in the ITU-R DBSG3 database [ITU-R, 2014]. These are the entries in the database for which the coordinates of both ends of the link are available, making it possible to determine the azimuth. The links' main characteristics are shown in Table II.

Fig. 7 shows the calculated values of $R_{\text {eff }}$ against the measured values of $R$ at the same time percentages for all datasets corresponding to the links in Table II. The values of $R_{\text {eff }}$ were obtained using eq. 5 . 
TABLE II - $\quad$ CHARACTERISTICS OF THE LINKS IN THE ITU-R DATABASE USED TO FIT THE EFFECTIVE RAINFALL RATE

\begin{tabular}{cccccc}
\hline Station & Country & Azimuth $\left(^{\circ}\right)$ & $\begin{array}{c}\text { Path length } \\
(\mathbf{k m})\end{array}$ & $\begin{array}{c}\text { Frequency } \\
(\mathbf{G H z})\end{array}$ & $\begin{array}{c}\text { Measurements } \\
\text { period (years) }\end{array}$ \\
\hline Uvaly & CZ & 75.04 & 15.30 & 14.92 & 4 \\
Mostova & CZ & 98.28 & 43.80 & 13.14 & 4 \\
Pisek & CZ & 205.03 & 39.40 & 13.03 & 4 \\
Strahov & CZ & 198.14 & 34.00 & 13.19 & 4 \\
Strahov & CZ & 198.14 & 34.00 & 13.10 & 4 \\
Piaseczno & PL & 224.55 & 15.40 & 11.50 & 4 \\
Piaseczno & PL & 224.55 & 15.40 & 18.60 & 4 \\
Dubna 3 & SU & 237.00 & 12.65 & 29.30 & 5 \\
Dubna 3 & SU & 237.00 & 12.65 & 19.30 & 8 \\
Dubna 3 & SU & 237.00 & 12.65 & 11.50 & 8 \\
Bradesco & BR & 259.98 & 12.79 & 14.55 & 2 \\
Cenesp & BR & 221.10 & 12.78 & 14.55 & 2 \\
Cenesp & BR & 221.10 & 12.78 & 18.61 & 2 \\
Scania & BR & 154.40 & 18.38 & 14.50 & 2 \\
Barueri & BR & 287.07 & 21.69 & 14.53 & 1 \\
Shell & BR & 126.48 & 7.48 & 18.59 & 1 \\
Paranapiacaba & BR & 124.27 & 42.99 & 14.52 & 2 \\
Brasília-STF & BR & 103.86 & 4.48 & 23.00 & 1 \\
Rio de Janeiro & BR & 216.91 & 6.55 & 23.00 & 2 \\
Fujitsu & MY & 107.04 & 1.40 & 32.60 & 1 \\
Yotsuya & JP & 347.37 & 2.30 & 33.40 & 3 \\
Akasaka & JP & 180.04 & 2.10 & 32.60 & 3 \\
Koenji & JP & 219.13 & 1.20 & 23.20 & 2 \\
Karagasaki & JP & 163.59 & 9.10 & 15.25 & 3 \\
Shiyakusyo & JP & 355.49 & 6.37 & 18.58 & 1 \\
\hline & & & & & \\
\hline
\end{tabular}

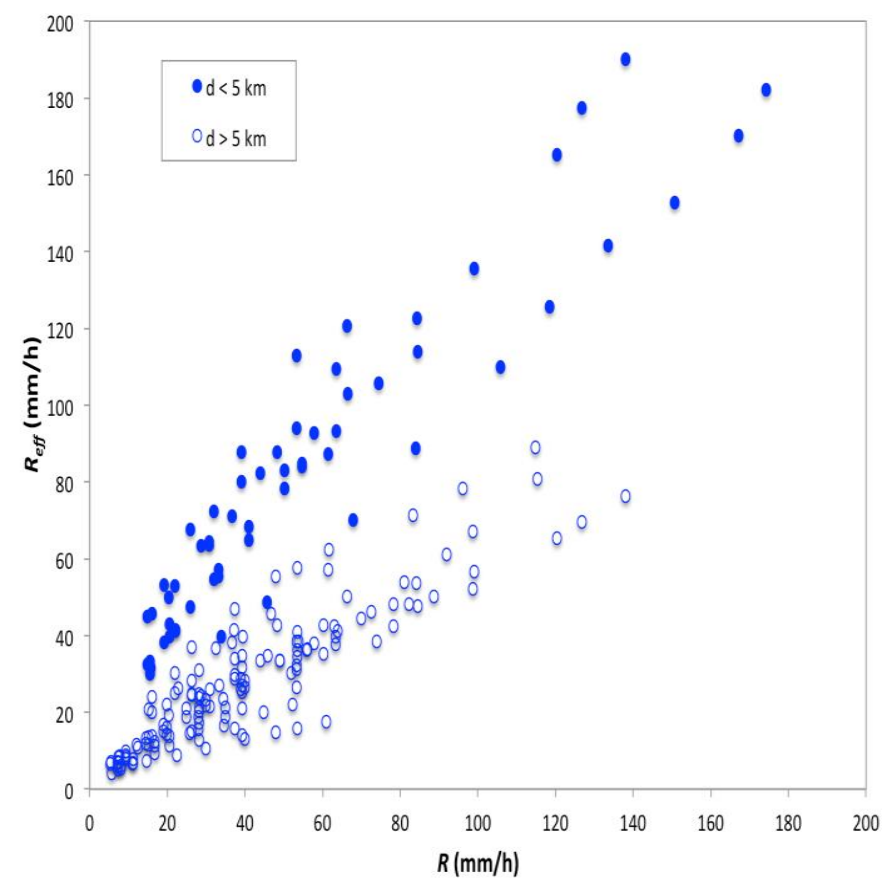

Fig. 7. Effective rainfall rate vs. point rainfall rate - 25 links in the ITU-R database 
It can be noted that, in this case, where both data from tropical and temperate regions are considered, the saturation of $R_{\text {eff }}$ clearly observed in fig. 4 is not present. Additionally, for links in the ITU-R database with path lengths smaller than $5 \mathrm{~km}$, the effective rainfall rate can be larger than the actual rainfall rate. This may be explained by the fact that the measured point rainfall rate values provided in the ITU-R database have a one-minute integration time. For low rainfall rates, the oneminute average may be smaller than the actual rainfall rate. For long links, this effect is compensated by the spatial non-uniformity of the rain field along the path and the effective rainfall rate becomes smaller than the measured rainfall rate. For short links the rain tends to be more uniform along the path resulting in an effective rainfall rate that can be larger than the rainfall rate measured with oneminute integration time.

This is not adequately modeled by eq. (6).. For the extended dataset, the variation of $R_{\text {eff }}$ with path length, shown in fig. 8, suggests the fitting by an exponential or a power-law function.

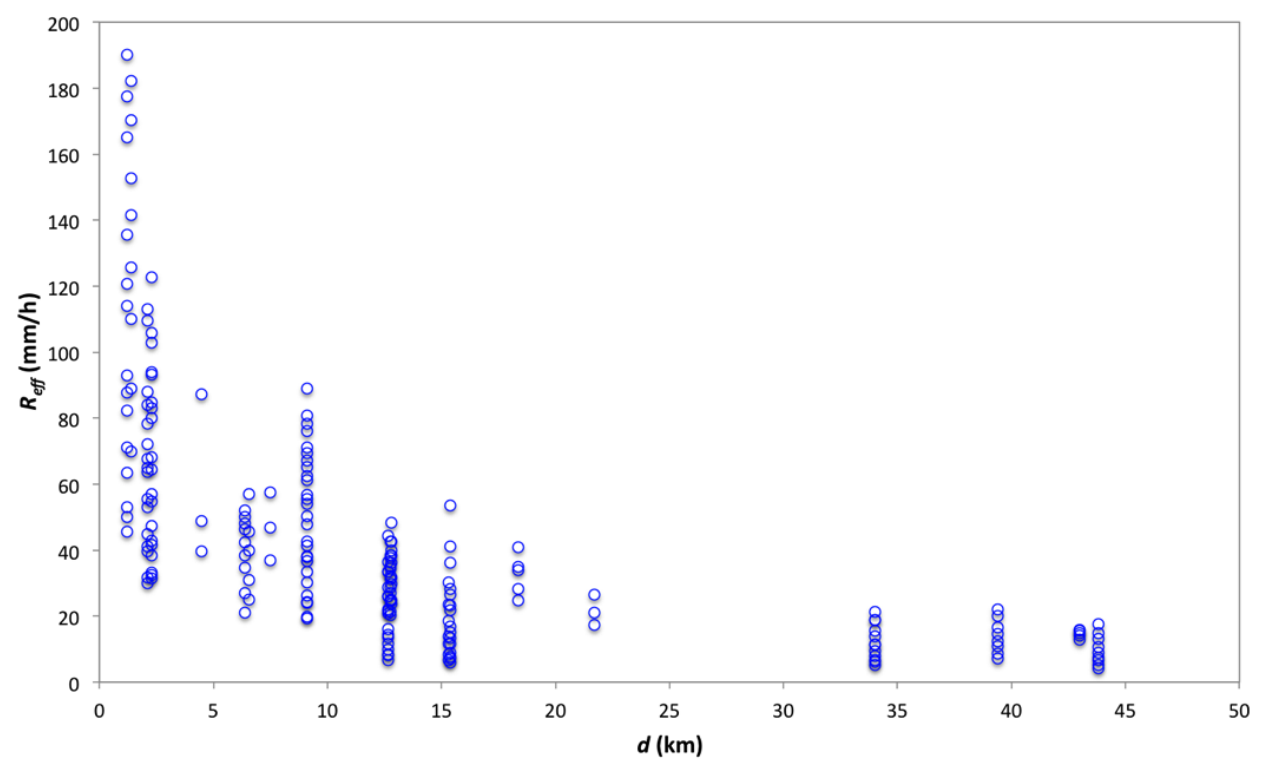

Fig. 8. Effective rainfall rate vs. path length - 25 links in the ITU-R database

The best fit including the wind direction factor (R-square=0.94) was obtained with the following expression:

$$
R_{\text {eff }}\left(R_{p}, d, \quad\right)=12.98 \times R^{0.59} \times d^{0.39} \times(1 \quad 0.105 \times) \text { for } 0 \quad 90^{0}
$$

The scatterplot of measured values of $R_{e f f}$ and the values estimated by eq. (10) is shown in Figure 9. 


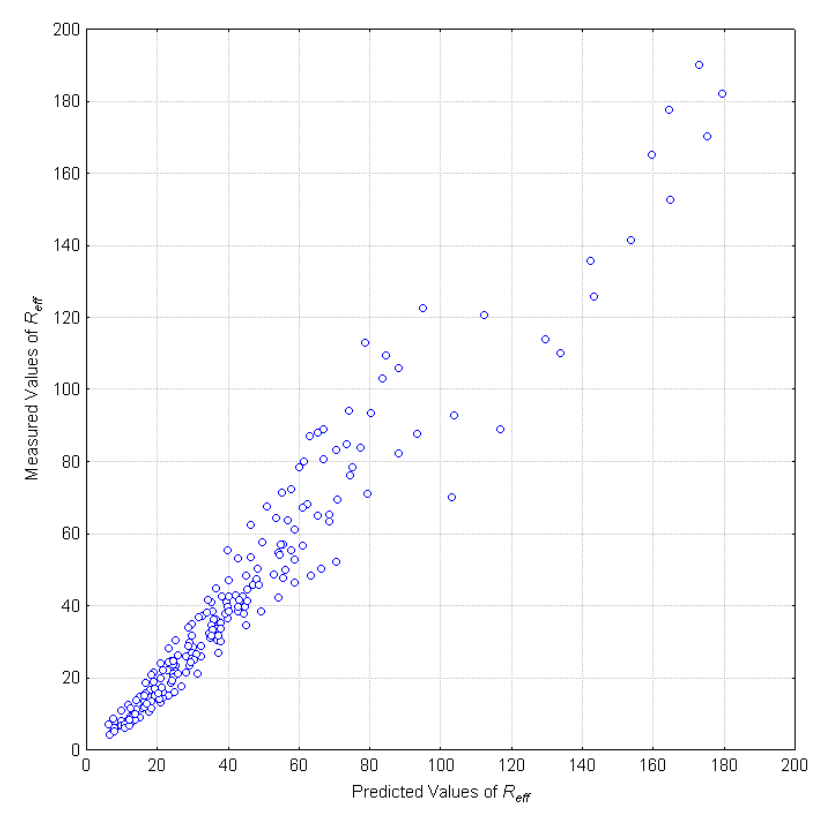

Fig. 9. Predicted versus observed values of $R_{\text {eff }}\left(R_{p}, d, \theta\right)-25$ links in the ITU-R database

To better evaluate the proposed method's accuracy, it was tested in comparison with the measured attenuation distributions and also with the distributions predicted by the current ITU-R method. The test variable recommended by the ITU-R [33] to access the accuracy of rain attenuation prediction methods is the weighted natural logarithm of the ratio between the predicted and measured values of the attenuation exceeded at a given percentage of time:

$$
\begin{array}{ll}
V_{i}=\left(\ln \frac{A_{m, i}}{A_{p, i}}\right)\left(\frac{A_{m . i}}{10}\right)^{0.2} & \text { for } A_{m, i}<10 \\
V_{i}=\ln \frac{A_{m, i}}{A_{p, i}} & \text { for } A_{m, i} \geq 10
\end{array}
$$

where $A_{m, i}$ and $A_{p, i}$ are the i-th measured and predicted values of attenuation, respectively. The mean and the standard deviation of the test variable values calculated for all links and percentages of time for which there are measured data available are used to evaluate the performance of each method.

Table III shows the mean value, standard deviation and r.m.s. value of the test variable for the proposed method and the ITU-R method, for percentages of time between $0.001 \%$ and $0.1 \%$. It should be noted that the values at the $0.001 \%$ probability level corresponds to a smaller number of observed events, limiting the statistical reliability of the results.

For this subset of the ITU-R databank, the method using the effective rainfall rate that is a function of path length and wind direction shows significant improvement over the ITU-R method. The overall r.m.s. error of the proposed method considering all probabilities is 0.251 , to be compared with 0.428 for the ITU-R method. 
TABLE III - $\quad$ PREDICTION ERRORS OF THE ITU-R P.530-15 METHOD AND THE PROPOSED METHOD

\begin{tabular}{ccccccc}
\hline & \multicolumn{2}{c}{ Average error } & \multicolumn{2}{c}{ Standard deviation } & \multicolumn{2}{c}{ R.M.S. error } \\
\hline $\mathbf{p ~ ( \% )}$ & ITU-R & Proposed & ITU-R & Proposed & ITU-R & Proposed \\
\hline 0.001 & -0.084 & 0.157 & 0.377 & 0.214 & 0.386 & 0.266 \\
0.003 & -0.150 & 0.090 & 0.335 & 0.200 & 0.367 & 0.220 \\
0.01 & -0.203 & 0.075 & 0.350 & 0.240 & 0.405 & 0.252 \\
0.03 & -0.282 & 0.024 & 0.373 & 0.274 & 0.468 & 0.276 \\
0.1 & -0.383 & -0.041 & 0.398 & 0.280 & 0.552 & 0.283 \\
\hline
\end{tabular}

\section{CONCLUSIONS}

A modified effective rainfall rate method is proposed for the prediction of rain attenuation in terrestrial links. In contrast with the method currently recommended by the ITU-R, the full rainfall rate distribution is taken into account to predict the attenuation distribution, avoiding extrapolations dependent on the percentage of time.

The method uses the concept of an effective rainfall rate to represent the temporal and spatial variations of rain intensity along the path. Based on measurements performed at converging links in three different tropical sites, it was found that the effective rainfall rate depends on the wind direction during rainy conditions, in addition to the measured rainfall rate and path length.

The method developed for tropical sites was extended for other climatic regions using data from additional links available in the ITU-R databanks, and the resulting prediction method shows significant improvement when tested in comparison the current ITU-R method.

\section{ACKNOWLEDGMENT}

CNPq (National Research Council, Brazil) supported this work under covenant 573939/2008-0 (INCT-CSF).

\section{REFERENCES}

[1] Oguchi, T., Attenuation of electromagnetic wave due to rain with distorted raindrops, J. Radio Res. Labs. (Japan), 33(7), 467-485, 1960.

[2] Oguchi, T., Attenuation of electromagnetic wave due to rain with distorted raindrops (Part II), J. Radio Res. Labs. (Japan), 11, 19-44, 1964.

[3] Drufuca, G., Rain attenuation statistics for frequencies above $10 \mathrm{GHz}$ from rain gauge observations, Journal Recherches Atmospheriques, vol 1-2, pp. 399-411, 1974.

[4] Olsen, R., D. Rogers, and D. Hodge, The $\mathrm{aR}^{\mathrm{b}}$ relation in the calculation of rain attenuation, IEEE Trans. Ant. Prop., 26(2), 318-329, 1978.

[5] Pruppacher, H. R., and R. L. Pitter, A semi-empirical determination of the shape of cloud and rain drops, J. Atmos. Sci., 28(1), 86-94, 1971.

[6] Oguchi, T., Scattering properties of Pruppacher-and-Pitter form raindrops and cross-polarization due to rain: calculations at 11,13, 193 and 34-8 GHz, Radio Sci., 12, 41-51, 1977.

[7] ITU-R Recommendation P.838-3, 2005, Specific attenuation model for rain for use in prediction methods, International Telecommunication Union, http://www.itu.int/rec/R-REC-P.838/en.

[8] Gibbins, C. J., and C. J. Walden, A study into the derivation of improved rain attenuation regression coefficients, Radiocommunications Agency Report No. AY4359, 2003, http://www.radio.gov.uk/topics/research/research-index.htm.

[9] Capsoni, C., and M. D'Amico, Morphological description of the rain structures in the Padana Valley, Proceedings of the Third European Conference on Radar Meteorology (ERAD), 541-544, 2004.

[10] Steiner, M. and R.A. Houze Jr., Sensitivity of estimated monthly convective rain fraction to the choice of Z-R relation, $J$ Appl. Meteor., 36, 452-462, 1997.

[11] Capsoni C., L. Luini, A. Paraboni and C. Riva, Stratiform and convective rain discrimination deduced from local P(R), IEEE Trans. Ant. Prop., 54(11), 3566-3569, 2006. 
[12] Houze, R.A., Stratiform precipitation in regions of convection, Bull. Amer. Meteor. Soc., 78, 2179-95, 1997Matricciani E., Physicalmathematical model of the dynamics of rain attenuation based on rain rate time series and a two-layer vertical structure of precipitation, Radio Science, vol. 31, no. 2, pp. 281-296, 1996.

[13] Matricciani E. (2008), Global formulation of the Synthetic Storm Technique to calculate rain attenuation only from rain rate probability distributions, IEEE Antennas and Propagation Society International Symposium, 1-4, 2008, doi: 10.1109/APS.2008.4619006.

[14] Maseng, T., and P. M. Bakken (1981), A Stochastic Dynamic Model of Rain Attenuation, IEEE Trans. Com., $29(5), 660-669,1981$.

[15] Lacoste, F., M. Bousquet, L. Castanet, F. Cornet, and J. Lemorton, Improvement of the ONERA-CNES rain attenuation time series synthesizer and validation of the dynamic characteristics of the generated fade events, Space Comm. Journal, 20(1-2), 45-59, 2005.

[16] Andrade, F. J. A., and Da Silva Mello, L., Rain Attenuation Time Series Synthesizer Based on the Gamma Distribution, IEEE Ant. Wireless Prop. Letters, 10, 1381-1384, 2011.

[17] Misme, P., and J. Fimbel, Theoretical and experimental determination of rain-induced attenuation on a radioelectric path, Ann. Téléc., 30, 149-158, 1975.

[18] Capsoni, C., F. Fedi, C. Magistroni, A. Paraboni, and A. Pawlina, Data and theory for a new model of the horizontal structure of rain cells for propagation applications, Radio Sci., 2293), 395-404, 1987.

[19] Paraboni, A., G. Masini, and A. Elia, The Effect of Precipitation on Microwave LMDS Networks - Performance Analysis using a Physical Raincell Model, IEEE J. on Selected Areas in Commun., 20(3), 615-619, 2002.

[20] Lin, S. H., A method for calculating rain attenuation distributions on microwave paths, Bell Syst. Tech. J., 1051-1086, 1975.

[21] Garcia Lopez, J.A., and J. Peiro, Simple rain attenuation prediction technique for terrestrial radio links, Elect. Letters, 19, 879-881, 1983.

[22] Moupfouma, F., Improvement of a rain attenuation prediction method for terrestrial microwave links, IEEE Trans. Ant. Prop., 32, $1368-1372,1984$.

[23] ITU-R Recommendation P.530-15, 2013, Propagation data and prediction methods required for the design of terrestrial line-of-sight systems, International Telecommunication Union, http://www.itu.int/rec/R-REC-P.530/en.

[24] Crane, R. K., Prediction of attenuation by rain, IEEE Trans. Commun., 28, 1717-1733, 1980

[25] Da Silva Mello, L., M. S. Pontes, R. M. de Souza and N. A. Pérez Garcia, Prediction of rain attenuation in terrestrial links using the full rainfall rate distribution, Elec. Letters, 43, 1442-1443, 2007.

[26] Da Silva Mello, Luiz and M. S. Pontes, Unified Method for the Prediction of Rain Attenuation in Satellite and Terrestrial Links, J. Micr. Optoelec. Elect. Appl., 11, 1-14, 2012.

[27] ITU-R Databank DBSG3, 2014, http://www.itu.int/pub/R-SOFT-SG3/en

[28] ITU-R Recommendation P.837-6, 2012, Characteristics of precipitation for propagation modeling, International Telecommunication Union, http://www.itu.int/rec/R-REC-P.837/en.

[29] Silva Mello, L. A. R, E. P. O. Costa, R. S. L. Souza, Rain attenuation measurements at 15 and 18 GHz, Electronics Letters, $40(11)$, 683-684, 2004.

[30] Draper, N. R., Smith, H. (1998). Applied Regression Analysis. Wiley-Interscience. ISBN 0-471-17082-8.

[31] ECMWF (2013), ERA-40, http://www.ecmwf.int/products/data/archive/descriptions/e4/.

[32] ITU-R Recommendation P.311-12, 2006, Acquisition, presentation and analysis of data in studies of tropospheric propagation, International Telecommunication Union, http://www.itu.int/rec/R-REC-P.311/en. 